\title{
A cross-sectional research of iodine status of pregnant women in Chongqing, south-west China
}

\author{
Ning Yaot (10, Chunbei Zhou†, Jun Xie and Shuang Zhou* \\ Department for Endemic Disease Control and Prevention, Chongqing Center for Disease Control and Prevention, \\ Chongqing 400042, People's Republic of China
}

Submitted 1 March 2019: Final revision received 15 July 2019: Accepted 2 August 2019: First published online 17 January 2020

\begin{abstract}
Objective: To investigate whether implementation of a universal salt iodization (USI) programme has sufficient effects on pregnant women in Chongqing, the present study evaluated the iodine nutritional status of pregnant women living in Chongqing by spot urinary iodine concentration (UIC), to provide scientific suggestions to better meet the specific iodine needs of this vulnerable group.

Design: Cross-sectional design.

Setting: A random spot urine sample and household table salt sample were provided by each participant.

Participants: A total of 2607 pregnant women from twenty-six of thirty-nine districts/counties in Chongqing participated.

Results: The overall median UIC of pregnant women was $171.80 \mu \mathrm{g} / \mathrm{l}$ (interquartile range $(\mathrm{IQR})=113.85-247.00 \mu \mathrm{g} / \mathrm{l})$ and $40.97 \%(n$ 1057) of participants were iodine insufficient. The median iodine in table salt samples was $25.40 \mathrm{mg} / \mathrm{kg}$ (IQR $=23 \cdot 10-28 \cdot 30 \mathrm{mg} / \mathrm{kg}$ ); $93.26 \%$ ( $n$ 2406) of samples examined were found to be adequately iodized. Iodine nutritional status was not significantly different according to table salt iodization category. Trimester was identified to be statistically associated with UIC $(P<0 \cdot 01)$. Seven districts/counties had median UIC below $150 \mu \mathrm{g} / 1$ and one district had median UIC of $277.40 \mu \mathrm{g} / \mathrm{l}$.

Conclusions: The USI programme in Chongqing prevents iodine deficiency generally, but does not maintain iodine status within adequate and recommended ranges throughout pregnancy. Usage of non-iodized or unqualified iodized salt and the slight change of dietary habits of iodized salt in Chongqing may present a substantial challenge to fight iodine-deficiency disorders; more efforts are needed to ensure adequate iodine intake during pregnancy besides the USI programme.
\end{abstract}

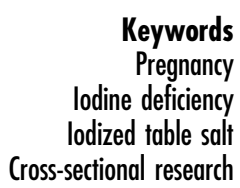

Iodine deficiency occurs when iodine intake falls below recommended levels. Inadequate iodine intake may affect all stages of life, especially during pregnancy, as iodine is an essential compound for producing thyroid hormones which play a critical role in normal metabolic activities and fetal development ${ }^{(1)}$. Absorption of iodine at sufficient level is essential for the fetus and mother's thyroid glands to function healthily ${ }^{(2)}$. The harmful effects due to low level of thyroid hormones in the blood are known collectively as iodine-deficiency disorders (IDD) ${ }^{(3)}$. The most devastating consequences of iodine deficiency for pregnant women include abortion, stillbirth and congenital anomalies, and

$\dagger$ These authors contributed equally to this work. for neonates and children include neonatal hypothyroidism and retarded mental and physical development ${ }^{(3)}$, with the most critical period being from the second trimester of pregnancy to the third year after birth ${ }^{(3)}$. IDD were one of the most serious public health threats in China in the 1990s, with at least 8 million endemic cretinism cases ${ }^{(1,4)}$. Pregnant women and young children are the most susceptible populations because they require higher iodine intake to maintain both maternal and neonatal normal neurodevelopment. In 1994, epidemiological studies conducted in Chongqing demonstrated that $41.48 \%$ of schoolchildren aged $7-14$ years showed visible signs of goitre, with a median urinary iodine concentration (UIC) of $53.14 \mu \mathrm{g} / \mathrm{l}$, and the iodine concentration in drinking-water was $3.34 \mu \mathrm{g} / \mathrm{l}$. Most of the household table 
salt samples investigated were non-iodized, and Chongqing was identified as an endemic area of IDD ${ }^{(5)}$.

Salt iodization is currently the most widely used strategy to control and eliminate IDD. China adopted salt iodization as its principal control strategy in $1993^{(6)}$ and established a compulsory universal salt iodization (USI) programme in 1995. As a municipality directly under the central government in the south-west of China, Chongqing introduced a USI programme in 1997. Considerable progress for the general population nationwide has been achieved after two decades' mandatory use of iodized salt. China had virtually eliminated IDD by $2000^{(6)}$, and surveillance data of the national evaluation in 2010 also suggested that many of the targets of the China IDD Elimination Program had been met as twenty-eight provinces had eliminated IDD and three had 'almost eliminated' it ${ }^{(7)}$. But regional differences in the iodine nutritional status of school-aged children and pregnant women among provinces still existed. According to China's 2011 National IDD Surveillance results ${ }^{(6)}$, in fourteen provinces including Chongqing (plus Xinjiang corps) the median UIC of pregnant women was in the optimal range of $150-249 \mu \mathrm{g} / \mathrm{l}$ and that of school-aged children was between 200 and $299 \mu \mathrm{g} / \mathrm{l}$, which is considered 'above requirements' by WHO. As the incidence of thyroid disease, in particular goitre, thyroiditis, hyper- and hypothyroidism and thyroid cancer, was reported to be rising in recent years ${ }^{(8)}$, the risk of excessive iodine intake was overestimated ${ }^{(9)}$, and iodine concentration in household table salt started to drop from $35 \mathrm{mg} / \mathrm{kg}$ $\pm 30 \%$ during $2000-2011$ to 20,25 or $30 \mathrm{mg} / \mathrm{kg} \pm 30 \%$ in 2012 (Chinese Standard GB 26878-2011). Each province has been mandated to choose its own iodine content standard, taking account of the actual iodine nutrition of the local population in order to prevent both iodine deficiency and iodine excess. Chongqing chose the highest level of $30 \mathrm{mg} / \mathrm{kg}$. Previous studies showed iodine deficiency still existed among some pregnant women even with generally adequate iodine intake ${ }^{(10-12)}$. It is important to regularly monitor the iodine status in the most susceptible and vulnerable groups because even mild iodine deficiency may impair neuropsychological and motor development in children ${ }^{(11)}$. The present study aimed to assess the iodine status of pregnant women in Chongqing after the implementation of new standards for salt iodization since 2012, in order to provide scientific suggestions to better meet the specific iodine needs of this vulnerable group.

\section{Methods}

\section{Study design and sample collection}

This was a cross-sectional study embedded in the 2016 China National IDD Surveillance Program led by the National Health Commission of the People's Republic of China. From May to October in 2017, twenty-six of thirtynine districts/counties were randomly chosen from
Chongqing according to China's national surveillance guidelines of the IDD surveillance programme ${ }^{(1,13)}$. In each surveillance county, five towns were randomly selected from five different geological locations (east, west, south, north and centre). In each selected town, a convenience sampling method was used to recruit twenty pregnant women into the study from one or two clinics where they attended the prenatal examination; pregnant women in an adjacent town could be selected as a supplement if there were fewer than twenty in the target town. Only those participants residing in the selected town for at least 6 months were qualified to enrol in the study. For each participant, approximately $10 \mathrm{ml}$ of a random spot midstream urine sample was collected. Each participant also provided 50-100 g of household table salt and completed a brief interview to gather information such as the date of birth, weeks of pregnancy, history of thyroid disease and intake of iodine-containing supplements. Written informed consents were obtained from all participants prior to enrolment. All procedures involving research study participants were approved by the Ethical Review Committee of Chongqing Center for Disease Control and Prevention.

\section{Determination of iodine concentration}

Iodine content in table salt was measured using a titration method with sodium thiosulfate (Chinese Standard GB/T 13025.7-2012). UIC was determined using arsenic-cerium catalytic spectrophotometry (Chinese Standard WS/T 107.1-2016). All fourteen laboratories testing the iodine content in salt and UIC were participants of an internal quality control and an external quality assurance programme run by the Chinese Center for Disease Control and Prevention. Iodine levels of $5 \%$ of urine and salt samples were re-examined in the reference laboratory of the Chongqing Center for Disease Control and Prevention for quality control purposes.

According to the epidemiological criteria for assessing iodine nutrition based on the median UIC of pregnant women recommended by WHO, iodine nutritional status is insufficient when the median UIC is less than $150 \mu \mathrm{g} / 1$ (mild deficiency, 100-150 $\mu \mathrm{g} / \mathrm{l}$; moderate and severe deficiency, $<100 \mu \mathrm{g} / \mathrm{l}$ ), adequate when the median UIC is between 150 and $249 \mu \mathrm{g} / \mathrm{l}$, above requirements when the median UIC is between 250 and $499 \mu \mathrm{g} / \mathrm{l}$, and excessive when the median UIC is above $500 \mu \mathrm{g} / \mathrm{l}^{(3)}$. Household table salt was classified into four groups: non-iodized salt with iodine content $<5 \mathrm{mg} / \mathrm{kg}$, inadequately iodized when between 5 and $21 \mathrm{mg} / \mathrm{kg}$, adequately iodized when between 21 and $39 \mathrm{mg} / \mathrm{kg}$, and excessively iodized when iodine content is $>39 \mathrm{mg} / \mathrm{kg}$.

\section{Statistical analysis}

Data were input in Microsoft Office Excel 2007 and data analysis was performed using the statistical software package SAS version 9.13. The Kolmogorov-Smirnov test was 
used to check for normality. Iodine content in table salt and UIC was summarized by median and interquartile range (IQR). The Kruskal-Wallis test was used to compare UIC between subgroups. Comparisons of iodine nutritional status between subgroups were done using the $\chi^{2}$ test. $P<0.05$ was considered to indicate a significant difference. Spearman correlation analysis was used to determine the relationship between gestational week, iodine content in table salt and UIC.

\section{Results}

A total of 2607 pregnant women participated in the study with a mean age of 28 (SD 5.26) years. Because twentyseven of them (1.04\%) self-reported a history of thyroid disease, which mostly was hypothyroidism, the final sample size was 2580 participants. According to trimester of pregnancy, $15.35 \%(n 396)$ of them were in the first trimester, $41.05 \%$ ( $n$ 1059) were in the second trimester and $43.60 \%$ ( $n 1125)$ were in the third trimester. UIC and salt iodine content values were non-normally distributed by the Kolmogorov-Smirnov test with $D$ statistic of 0.1479 and $0 \cdot 1432$, respectively $(P<0 \cdot 01)$.

The overall median UIC of the pregnant women was $171.80 \mu \mathrm{g} / \mathrm{l}(\mathrm{IQR}=113.85-247.00 \mu \mathrm{g} / \mathrm{l}) ; 40.97 \%(n 1057)$ of the participants were iodine insufficient, of whom $47.30 \%$ ( $n$ 500) were found to have mild deficiency and $52.70 \%$ ( $n 557)$ to have moderate and severe deficiency. Among the others, $35.23 \%(n 909)$ were iodine sufficient, $19.92 \%$ ( $n$ 514) were above requirements and 3.88\% ( $n$ 100) were iodine excessive. The median iodine content of the table salt was $25.40 \mathrm{mg} / \mathrm{kg}(\mathrm{IQR}=23 \cdot 10-28 \cdot 30 \mathrm{mg} / \mathrm{kg})$. Out of the 2580 participants who provided table salt samples, $0.27 \%(n 7)$ were detected to be non-iodized salt and $99.73 \%(n 2573)$ were iodized salt, but $5.23 \%(n 135)$ and $1.24 \%(n 32)$ of them were determined to be inadequately or excessively iodized, respectively. A large proportion of $93.26 \%$ ( $n$ 2406) was found to be adequately iodized salt (Table 1).
No association between iodine content in table salt and UIC was identified $(P=0 \cdot 176)$.

Women in the first trimester had a significantly higher median UIC $(189.70 \mu \mathrm{g} / \mathrm{l})$ than those in the second and third trimester $(P<0 \cdot 01)$. Multiple comparisons showed there was no statistical difference between UIC of participants in the second and third trimester $(Z=1.69$, $P=0.0898)$. The median UIC was not statistically different among participants who provided different categories of table salt iodization using the Kruskal-Wallis test $\left(\chi^{2}=5 \cdot 63, P=0 \cdot 1312\right.$; Table 1$)$.

A significant difference in iodine nutritional status was observed among the three trimesters of pregnancy $\left(\chi^{2}=17.25, P<0.01\right)$. The proportions of women in the first trimester who were iodine sufficient $(39.14 \%)$ or above requirements $(26.01 \%)$ were higher than those in the second $(35.51$ and $19.55 \%)$ and third trimester (33.60 and $18.13 \%)$. More women were found to be iodine insufficient in the third trimester $(44.71 \%)$ than in the first $(31.06 \%)$ and second trimester $(40.70 \%)$. Iodine status was not significantly different according to table salt iodization category $\left(\chi^{2}=4.77, P=0.8537\right.$; Table 2$)$.

The median UIC of twenty-seven women who confirmed having a history of thyroid disease was $183.60 \mu \mathrm{g} / \mathrm{l}$ (IQR $=144.40-253.50 \mu \mathrm{g} / \mathrm{l})$, one of them consumed noniodized salt and the others (96.30\%) consumed adequately iodized salt. According to the WHO's criteria of UIC, $44.44 \%$ ( $n 12$ ) of them were iodine sufficient, $29.63 \%(n 8)$ were iodine insufficient, $22.22 \%(n 6)$ were above requirements and $3.70 \%(n 1)$ was iodine excessive. Only $0.58 \%$ (15/2607) of pregnant women investigated took iodine supplements; among them, eight women were previously diagnosed with hypothyroidism and reported taking Euthyrox, and the other seven did not confirm having thyroid disease. The median UIC of the fifteen women who reported having used iodine supplements was $117.20 \mu \mathrm{g} / \mathrm{l} \quad(\mathrm{IQR}=77 \cdot 30$ $213.90 \mu \mathrm{g} / \mathrm{l}$ ), one of them consumed inadequately iodized salt and the others used adequately iodized salt. Half of them (53.33\%) were found to be iodine insufficient, about

Table 1 Urinary iodine concentration (UIC) according to trimester of pregnancy and table salt iodization category* of pregnant women ( $n 2607)$ in twenty-six districts/counties of Chongqing, China, 2017

\begin{tabular}{|c|c|c|c|c|c|}
\hline \multirow[b]{2}{*}{ Characteristic } & \multirow[b]{2}{*}{$n$} & \multirow[b]{2}{*}{$\%$} & \multicolumn{2}{|c|}{$\mathrm{UIC}(\mu \mathrm{g} / \mathrm{l})$} & \multirow[b]{2}{*}{$P$} \\
\hline & & & Median & IQR & \\
\hline Trimester & & & & & $<0.01$ \\
\hline First trimester & 396 & $15 \cdot 35$ & $189 \cdot 70$ & $132 \cdot 65-262 \cdot 60$ & \\
\hline Second trimester & 1059 & 41.05 & 171.90 & $115 \cdot 30-247 \cdot 40$ & \\
\hline Third trimester & 1125 & 43.60 & 163.00 & $108.90-239.50$ & \\
\hline Table salt & & & & & 0.1312 \\
\hline Non-iodized & 7 & 0.27 & 88.50 & $32 \cdot 20-202 \cdot 50$ & \\
\hline Inadequately iodized & 135 & $5 \cdot 23$ & $162 \cdot 20$ & $96 \cdot 10-247 \cdot 40$ & \\
\hline Adequately iodized & 2406 & $93 \cdot 26$ & $172 \cdot 00$ & $114.30-247.00$ & \\
\hline Excessively iodized & 32 & $1 \cdot 24$ & $180 \cdot 715$ & $135 \cdot 05-241.185$ & \\
\hline
\end{tabular}

$\mathrm{IQR}$, interquartile range.

*Non-iodized, iodine content $<5 \mathrm{mg} / \mathrm{kg}$; inadequately iodized, iodine content $5-21 \mathrm{mg} / \mathrm{kg}$; adequately iodized, iodine content $21-39 \mathrm{mg} / \mathrm{kg}$; excessively iodized, iodine content $>39 \mathrm{mg} / \mathrm{kg}$. 
Table 2 lodine status according to trimester of pregnancy and table salt iodization category* of pregnant women $(n 2607)$ in twenty-six districts/counties of Chongqing, China, 2017

\begin{tabular}{|c|c|c|c|c|c|c|c|c|c|}
\hline \multirow[b]{2}{*}{ Characteristic } & \multicolumn{2}{|c|}{$\begin{array}{c}\text { lodine } \\
\text { insufficient }\end{array}$} & \multicolumn{2}{|c|}{ lodine sufficient } & \multicolumn{2}{|c|}{$\begin{array}{c}\text { Above } \\
\text { requirements }\end{array}$} & \multicolumn{2}{|c|}{$\begin{array}{l}\text { lodine } \\
\text { excessive }\end{array}$} & \multirow[b]{2}{*}{$P$} \\
\hline & $n$ & $\%$ & $n$ & $\%$ & $n$ & $\%$ & $n$ & $\%$ & \\
\hline Trimester & & & & & & & & & $<0.01$ \\
\hline First trimester & 123 & 31.06 & 155 & 39.14 & 103 & $26 \cdot 01$ & 15 & 3.79 & \\
\hline Second trimester & 431 & $40 \cdot 70$ & 376 & $35 \cdot 51$ & 207 & 19.55 & 45 & 4.25 & \\
\hline Third trimester & 503 & 44.71 & 378 & 33.60 & 204 & $18 \cdot 13$ & 40 & 3.56 & \\
\hline Table salt & & & & & & & & & 0.8537 \\
\hline Non-iodized & 5 & 71.43 & 1 & 14.29 & 1 & 14.29 & 0 & 0.00 & \\
\hline Inadequately iodized & 58 & 42.96 & 46 & 34.07 & 26 & 19.26 & 5 & 3.70 & \\
\hline Adequately iodized & 982 & $40 \cdot 81$ & 849 & 35.29 & 480 & 19.95 & 95 & 3.95 & \\
\hline Excessively iodized & 12 & 37.50 & 13 & $40 \cdot 63$ & 7 & 21.88 & 0 & 0.00 & \\
\hline
\end{tabular}

${ }^{*}$ Non-iodized, iodine content $<5 \mathrm{mg} / \mathrm{kg}$; inadequately iodized, iodine content $5-21 \mathrm{mg} / \mathrm{kg}$; adequately iodized, iodine content $21-39 \mathrm{mg} / \mathrm{kg}$; excessively iodized, iodine content $>39 \mathrm{mg} / \mathrm{kg}$.

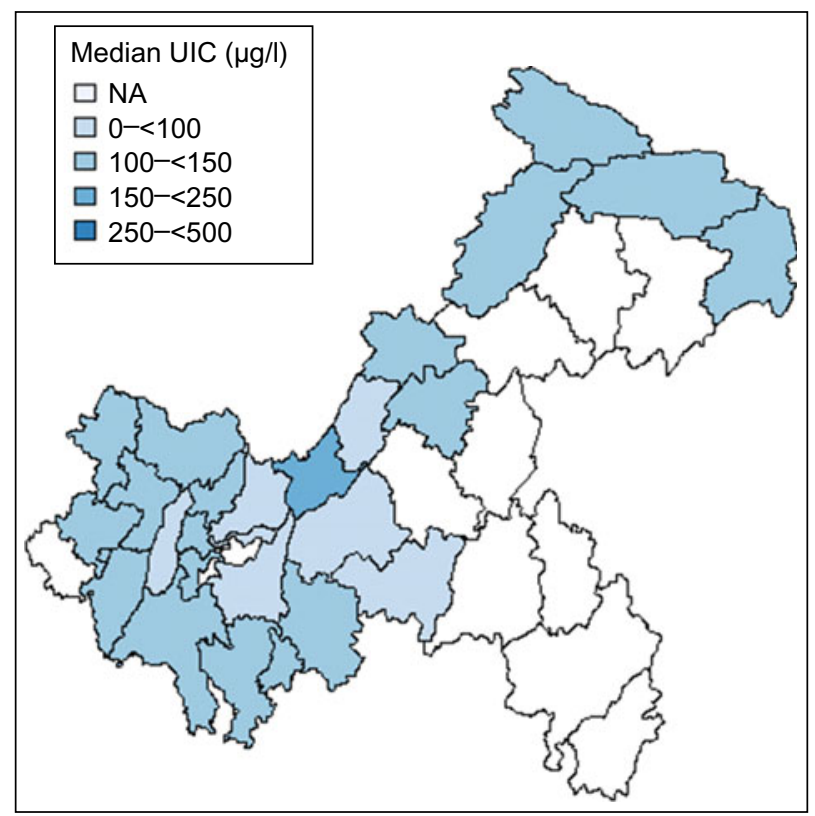

Fig. 1 (colour online) Distribution of median urinary iodine concentration (UIC) of pregnant women (n2607) over twentysix districts/counties of Chongqing, China, 2017 (NA, not investigated in this study)

one-third of them $(33.33 \%)$ were iodine sufficient and two (13.33\%) were above requirements.

Among the twenty-six districts/counties of Chongqing, participants from seven districts/counties had median UIC below $150 \mu \mathrm{g} / \mathrm{l}$ and one district had a median UIC of $277.40 \mu \mathrm{g} / \mathrm{l}$, which were presumed to be iodine insufficient and above requirements, respectively; the median UIC of the other eighteen areas was in the optimal range of iodine sufficient. Dianjiang County had the lowest median UIC of $121.00 \mu \mathrm{g} / \mathrm{l}$ and Changshou District had the highest median UIC of $277.40 \mu \mathrm{g} / \mathrm{l}$. The centre, west and majority of northeast areas were identified to be iodine sufficient with median UIC between 150 and $249 \mu \mathrm{g} / \mathrm{l}$ (Fig. 1). The median iodine content of table salt samples from all investigated locations was between 21 and $39 \mathrm{mg} / \mathrm{kg}$, in accordance with the provincial standard of Chongqing.

\section{Discussion}

Chongqing has achieved the goal of elimination of IDD since 2010 through implementation of the national USI programme. Because China has set an option of 20, 25 or $35 \mathrm{mg} / \mathrm{kg} \pm 30 \%$ for the iodine concentration of iodized salt, each province had chosen the optimal level according to local monitoring data. Compared with other research in different provinces of China, the overall median UIC of pregnant women in Chongqing $(171.90 \mu \mathrm{g} / \mathrm{l})$ obtained in the present study is lower than that of Henan Province $(204.20 \mu \mathrm{g} / \mathrm{l}$ in 2013 and $202.50 \mu \mathrm{g} / \mathrm{l}$ in 2014), but higher than in Zhejiang $(130.47 \mu \mathrm{g} / \mathrm{l})$ and Fujian Provinces $(136.60 \mu \mathrm{g} / 1$ of Xiamen city), which did not meet the requirement level recommended by the $\mathrm{WHO}^{(14)}$. Zhejiang and Fujian had adopted the new provincial standard for iodized salt of $25 \mathrm{mg} / \mathrm{kg}$ in 2012 and then found pregnant women overall were iodine deficient in the following years ${ }^{(1,12)}$. Inadequate iodine intake in the two coastal provinces may be related to their lower provincial standard of iodized table salt. It has been found to be efficient to choose a higher level of iodine content in salt, like in Chongqing and Henan (both are inland provinces), to meet the iodine intake needs of pregnant women.

Chongqing is an inland municipality far from the coastline, so people living in Chongqing may have been consuming less seafood like saltwater fish and seaweed which are also sources of iodine in addition to iodized salt. A study conducted in 2013 showed that iodine concentration of drinking-water in Chongqing was $1.50 \mu \mathrm{g} / \mathrm{l}^{(4)}$, indicating that the environment is universally lacking iodine according to the national criteria (Chinese Standard GB 16005-2009). In other places that have both coastal and inland areas, it was found that coastal residents had lower 
median UIC and lower percentage of iodized salt than the inland residents due to low consumption of iodized salt and easy access to sea salt without added iodine ${ }^{(1,15)}$. It has been found that the main dietary source of iodine of local inhabitants in the coastal regions ${ }^{(16)}$ as well as in Chongqing is iodized table salt.

Trimester was identified to be statistically associated with UIC, with the lowest median UIC recorded in the third trimester and the highest median UIC in the first, consistent with similar studies conducted in Zhejiang Province, Switzerland, Iran and Japan ${ }^{(1,17-19)}$. Frequency distributions of iodine insufficiency were more frequently represented in the second or third trimester $v$. the first trimester of pregnancy. The decreasing UIC throughout pregnancy might be explained by increased renal iodine clearance during early gestation and increased iodine shift from the maternal circulation to the growing fetal-placental unit later on ${ }^{(17)}$, as well as gradual decreased consumption of iodized salt in the second or third trimester because of increased oedema by gestational age ${ }^{(1)}$. The iodine status of pregnant women is important for fetal growth and neurodevelopment ${ }^{(20)}$. The results demonstrated that the USI programme in Chongqing as well as in other iodine-adequate areas ${ }^{(21)}$ prevents iodine deficiency generally, but does not maintain iodine status within adequate and recommended ranges throughout pregnancy, and more efforts are needed to ensure adequate iodine intake during pregnancy besides the USI programme.

Despite the present results showing general iodine sufficiency, $40.85 \%$ ( $n$ 1065) of participants were iodine insufficient. Especially among those using adequately iodized table salt, $40.81 \%$ of them were still identified as iodine deficient, indicating that there was still a proportion of pregnant women with iodine insufficient status in some areas of Chongqing. Our study found no significant association between UIC of pregnant women and different iodine content in household table salt, which is different from other studies ${ }^{(11,12)}$ and could be explained by the following two reasons. First, research has shown that iodized salt contributes $63.50 \%$ of food iodine, but $24.60 \%$ of this iodine is lost in cooking ${ }^{(16)}$. Second, because rates of some preventable, chronic and diet-related diseases have continued to rise over the past few decades, some authorities have provided guidelines for choosing a healthy diet in order to prevent these non-communicable diseases. The WHO recommends reducing salt intake to $5 \mathrm{~g} /$ person per $\mathrm{d}^{(22)}$, the US Department of Health and Human Services and US Department of Agriculture have recommended consuming less than $2300 \mathrm{mg} \mathrm{Na} / \mathrm{d}$ (equal to $5.8 \mathrm{~g} \mathrm{salt} / \mathrm{d})^{(23)}$, and China has set a criterion of $6 \mathrm{~g}$ salt/ person per $\mathrm{d}$ by the Chinese Dietary Guidelines (version 2007 and 2016). Therefore, dietary salt consumption has declined among the whole population ${ }^{(24)}$ in recent years, but a salt intake below $6 \mathrm{~g} / \mathrm{d}$ in pregnancy may cause iodine deficiency in pregnant women because they may need more iodine intake during pregnancy.
Our study showed that the overall iodine status of pregnant women in Chongqing was sufficient, but regional difference still exists. A minority of districts/counties have been assessed as iodine deficient with adequately iodized table salt. Pregnant women in five districts and two suburban counties appeared to be iodine deficient and iodine sufficiency was found in the outer suburban districts and rural counties. This regional difference may be attributed to population-to-population variation in the consumption of iodized salt, which was a limitation not thoroughly investigated in the present study. High salt intake in the Chinese population in Chongqing has been found using $24 \mathrm{~h}$ urinary $\mathrm{Na}$ excretion in previous research, and people living in rural areas with lower educational levels had a higher salt intake and several unhealthy dietary habits ${ }^{(25)}$. This emphasizes that education plays an important role in public health for maintaining a healthy diet and lifestyle, which might explain the regional differences observed in our study.

According to the Chinese National Standard of IDD Elimination (GB 16006-2008), the rate of utilization of iodized salt at the household level (99.73\%) and the percentage of adequately iodized salt $(93.51 \%, 2406 / 2573)$ obtained in the present study satisfied the national standard ( $>95 \%$ and $>90 \%$, respectively). Only a small proportion of the table salt provided was detected to be non-iodized or inadequately/excessively iodized, indicating that noniodized salt or unqualified iodized salt was indeed available on the market. At the beginning of introduction of USI, there was a mandatory implementation of selling only iodized salt on the market to the population in iodinedeficient areas through national legislation ${ }^{(26)}$, but the salt monopoly has been relaxed after elimination of IDD had been achieved in Chongqing, as well as in other provinces in China ${ }^{(1,14)}$. From 1 January 2017, the state council initiated a reformation of the salt industry, cancelling the regional restrictions on production and marketing of household table salt. The existence of non-iodized or unqualified iodized salt on market shelves of Chongqing and the change in dietary habits of iodized salt use may present a substantial challenge to sustainably eliminate IDD.

There are some limitations in our research. First, a random spot urine sample was collected for testing, which might be affected by variability in daily water intake ${ }^{(27)}$. Some research has reported the creatinine-standardized urinary concentration instead of UIC so as to minimize the variation due to dilution and urine volume, which both vary depending on different factors of pregnancy $(11,17,28)$. So, median creatinine-standardized UIC might be more reliable to assess iodine nutrition in pregnancy. Second, we did not further investigate the dietary iodine sources of these pregnant women. Our study showed that only $0.58 \%$ of pregnant women took iodine supplements, far less than in Zhejiang Province $(5 \%)^{(1)}$ and in other countries with official suggestion of taking iodine 
supplements ${ }^{(29)}$. Similar research showed that dietary factors such as use of iodine supplements and intake of dairy products were significantly associated with $\mathrm{UIC}^{(27,28,30,31)}$. Further studies should collect the dietary data of pregnant women in order to analyse the association between iodine status and dietary factors besides iodized salt intake.

\section{Conclusion}

In conclusion, iodine deficiency was found in $40.97 \%$ of pregnant women living in Chongqing with low iodine content in drinking-water. The daily diet including iodized table salt of pregnant women does not secure a sufficient iodine intake. There is an urgent need to provide evidence-based recommendations on ensuring adequate iodine nutrition in pregnancy.

\section{Acknowledgements}

Acknowledgements: The authors thank all the staff from Centers for Disease Control and Prevention of the twenty-six districts/counties in Chongqing involved in this study for their fieldwork. They also thank the pregnant women for their participation in the study. Financial support: This work was supported by the Chongqing Municipal Health and Family Planning Commission (grant number 2016MSXM100); the institution is now renamed as Chongqing Municipal Health Commission. Chongqing Municipal Health Commission had no role in the design, analysis or writing of this article. Conflict of interest: None. Authorship: Z.S. and X.J. contributed the design of the study and data acquisition. Z.C.B. and Y.N. performed all the statistical analyses and contributed to the write up. Z.S. revised it and approved the final version to be submitted. All authors read and approved the final manuscript. Ethics of buman subject participation: This study was conducted according to the guidelines laid down in the Declaration of Helsinki and all procedures involving research study participants were approved by the Ethical Review Committee of Chongqing Center for Disease Control and Prevention. Written informed consent was obtained from all participants prior to enrolment.

\section{References}

1. Wang Z, Xing M, Zhu W et al. (2018) Iodine deficiency in Zhejiang pregnant women in the context of universal salt iodization programme. Sci Rep $\mathbf{8}, 8835$.

2. Isiklar Ozberk D, Kutlu R, Kilinc I et al. (2019) Effects of mandatory salt iodization on breast milk, urinary iodine concentrations, and thyroid hormones: is iodine deficiency still a continuing problem? J Endocrinol Invest 42, 411-418.
3. World Health Organization (2007) Assessment of Iodine Deficiency Disorders and Monitoring their Elimination, 3rd ed. Geneva: WHO.

4. Meng F, Zhao R, Liu P et al. (2013) Assessment of iodine status in children, adults, pregnant women and lactating women in iodine replete areas of China. PLoS One $\mathbf{8}$, e81294.

5. Wang Z (2004) Iodine deficiency disorders in Chongqing and strategy study on prevention and control. Master's Thesis, Army Medical University.

6. Coding K, Chen Z, Shen H et al. (2014) China: leading the way in sustained IDD elimination. IDD Newsletter, May 2014. https://www.ign.org/newsletter/idd_may14_ china.pdf (accessed November 2019).

7. Sun D, Codling K, Chang S et al. (2017) Eliminating iodine deficiency in China: achievements, challenges and global implications. Nutrients $\mathbf{9}, 361$.

8. Sun X, Shan Z \& Teng W (2014) Effects of increased iodine intake on thyroid disorders. Endocrinol Metab 29, 240-247.

9. Laurberq P, Bülow Pedersen I, Knudsen N et al. (2001) Environmental iodine intake affects the type of nonmalignant thyroid disease. Thyroid 11, 457-469.

10. Gyamfi D, Wiafe YA, Danquah KO et al. (2018) Urinary iodine concentration and thyroid volume of pregnant women attending antenatal care in two selected hospitals in Ashanti Region, Ghana: a comparative cross-sectional study. BMC Pregnancy Childbirth 18, 166.

11. Konrade I, Kalere I, Strele I et al. (2015) Iodine deficiency during pregnancy: a national cross-sectional survey in Latvia. Public Health Nutr 18, 2990-2997.

12. Mao G, Zhu W, Mo Z et al. (2018) Iodine deficiency in pregnant women after the adoption of the new provincial standard for salt iodization in Zhejiang Province, China. BMC Pregnancy Childbirth 18, 313.

13. National Health Commission of the People's Republic of China (2016) The China's national surveillance guidelines of iodine deficiency disorders programme (in Chinese). http://www.nhc.gov.cn/jkj/s5873/201604/950811922fb944b 5ab3b59e4ae21a3a3.shtml (accessed January 2020).

14. Yang J, Zhu L, Li X et al. (2016) Iodine status of vulnerable populations in Henan Province of China 2013-2014 after the implementation of the new iodized salt standard. Biol Trace Element Res 173, 7-13.

15. Ghattas H, Francis S, El Mallah C et al. (2017) Lebanese children are iodine deficient and urinary sodium and fluoride excretion are weak positive predictors of urinary iodine. EurJ Nutr 56, 749-755.

16. Wu Y, Li X, Chang S et al. (2012) Variable iodine intake persists in the context of universal salt iodization in China. J Nutr 142, 1728-1734.

17. Brander L, Als C, Buess H et al. (2003) Urinary iodine concentration during pregnancy in an area of unstable dietary iodine intake in Switzerland. J Endocrinol Invest 26, 389-396.

18. Ainy E, Ordookhani A, Hedayati M et al. (2007) Assessment of intertrimester and seasonal variations of urinary iodine concentration during pregnancy in an iodine-replete area. Clin Endocrinol (Oxf) 67, 577-581.

19. Fuse Y, Ohashi T, Yamaguchi S et al. (2011) Iodine status of pregnant and postpartum Japanese women: effect of iodine intake on maternal and neonatal thyroid function in an iodine-sufficient area. J Clin Endocrinol Metab 96, 3846-3854.

20. Xiao Y, Sun H, Li C et al. (2018) Effect of iodine nutrition on pregnancy outcomes in an iodine-sufficient area in China. Biol Trace Elem Res 182, 231-237.

21. Mioto VCB, Monteiro A, de Camargo RYA et al. (2018) High prevalence of iodine deficiency in pregnant women living in adequate iodine area. Endocr Connect 7, 762-767. 
22. World Health Organization (2012) Guideline: Sodium Intake for Adults and Children. Geneva: WHO.

23. US Department of Health and Human Services \& US Department of Agriculture (2015) 2015-2020 Dietary Guidelines for Americans, 8th ed. http://health.gov/dietaryguidelines/ 2015/guidelines/ (accessed November 2019).

24. Ma D, Sakai H, Wakabayashi C et al. (2017) The prevalence and risk factor control associated with noncommunicable diseases in China, Japan, and Korea. J Epidemiol 27, 568-573.

25. Yamori Y, Liu L, Mu L et al. (2002) Diet-related factors, educational levels and blood pressure in a Chinese population sample: findings from the Japan-China Cooperative Research Project. Hypertens Res 25, 559-564.

26. China Food and Drug Administration (1994) Regulation on Eliminating Iodine Deficiency Disorders through Universal Salt Iodization (in Chinese). http://samr.cfda.gov.cn/WS01/ CL1601/91167.html (accessed November 2019).
27. Dahl L, Wik Markhus M, Sanchez PVR et al. (2018) Iodine deficiency in a study population of Norwegian pregnant women-results from the little in Norway study (LiN). Nutrients 10, 513

28. Bath SC, Furmidge-Owen VL, Redman CW et al. (2015) Gestational changes in iodine status in a cohort study of pregnant women from the United Kingdom: season as an effect modifier. Am J Clin Nutr 101, 1180-1187.

29. Zimmermann M \& Delange F (2004) Iodine supplementation of pregnant women in Europe: a review and recommendations. Eur J Clin Nutr 58, 979-984.

30. Zygmunt A, Adamczewski Z, Zygmunt A et al. (2015) An assessment of the effectiveness of iodine prophylaxis in pregnant women - analysis in one of reference gynaecological-obstetric centres in Poland. Endokrynol Polska 66, 404-411.

31. Andersen S, Sørensen L, Krejbjerg A et al. (2013) Iodine deficiency in Danish pregnant women. Dan Med J 60, A4657. 